\title{
Capacidade fotossintética de plantas de algodoeiro infectadas por ramulose e supridas com silício
}

\author{
Antonia Mirian Nogueira de Moura Guerra ( $\left.{ }^{1}\right)$; Fabrício Ávila Rodrigues ( ${ }^{2}$ ); Tricia Costa Lima (3); \\ Paulo Geraldo Berger ( $\left.{ }^{4 *}\right)$; Angélica Fátima Barros $\left({ }^{2}\right)$; Yasmin Cristina Rodrigues da Silva $\left({ }^{2}\right)$ \\ (1) Universidade Federal do Oeste do Pará (UFOPA), Instituto de Biodiversidade e Florestas, 68035-110 Santarém (PA), Brasil. \\ (2) Universidade Federal de Viçosa (UFV), Departamento de Fitopatologia, Laboratório Interação Planta-Patógeno, $36570-000$ Viçosa \\ (MG), Brasil. \\ (3) Universidade Estadual do Goiás (UEG), Unidade Universitária de Palmeiras de Goiás, 76190000 Palmeiras de Goiás (GO) Brasil. \\ (4) UFV, Departamento de Fitotecnia, Produção Vegetal, 36570-000 Viçosa (MG), Brasil. \\ $\left({ }^{*}\right)$ Autor correspondente: pgberger@ufv.br
}

Recebido: 25/ago./2013; Aceito: 9/jan./2014

\section{Resumo}

Nas plantas atacadas por patógenos ocorrem danos nas células do mesofilo, colonização dos espaços intra e intercelulares e fechamento de estômatos, afetando a transpiração, influxo do $\mathrm{CO}_{2}$ e taxa fotossintética. O uso de silício (Si) é importante para reduzir a intensidade de inúmeras doenças em várias espécies de plantas, além de ter um efeito positivo sobre a capacidade fotossintética. Objetivou-se com este estudo investigar o efeito do Si sobre a capacidade fotossintética de plantas de algodoeiro das cultivares BRS Araçá e FM 993 infectadas por Colletotrichum gossypii var. cephalosporioides supridas (+Si) ou não (-Si) com Si. Avaliaram-se as variáveis de trocas gasosas: taxa de assimilação líquida de carbono $(A)$, condutância estomática $\left(g_{s}\right)$, transpiração $(E)$, razão entre a concentração interna e ambiente de $\mathrm{CO}_{2}\left(C_{i} / C_{\mathrm{a}}\right)$, a eficiência instantânea no uso da água $(A / E)$ e a concentração de pigmentos. Houve redução de $A, g_{s}$, fixação de carbono, concentrações de clorofila a $\left(c l_{a}\right)$, clorofila b $\left(c l_{b}\right)$ e carotenoides, matéria seca total (MST) e aumento na $E$ e na A/E. Com o fornecimento de Si, as plantas das duas cultivares de algodoeiro aumentaram a $A$ devido ao aumento na $g_{s}$ e na fixação de $\mathrm{CO}_{2}$, além de no uso mais eficiente da água. $\mathrm{O}$ suprimento de Si aumentou as concentrações de $\mathrm{Cl}_{\mathrm{a}}, \mathrm{Cl}_{\mathrm{b}}$ e carotenoides e MST nas duas cultivares. O Si afetou a fisiologia das plantas de algodoeiro infectadas por C. gossypii var. cephalosporioides, aumentando a resistência à ramulose devido a incrementos na capacidade fotossintética, na concentração de pigmentos e no acúmulo de biomassa.

Palavras-chave: Colletotrichum gossypii var. cephalosporioides, fotossíntese, trocas gasosas.

\section{Photosynthetic capacity of cotton boll rot infected plants and supplied with silicon}

\begin{abstract}
In plants attacked by pathogens, occurring cell damage of the mesophyll, colonization of intra and intercellular spaces and closing of stomata, affecting perspiration, influx of $\mathrm{CO}_{2}$ and the photosynthetic rate. The use of Silicon ( $\mathrm{Si}$ ) is important to reduce the intensity of numerous diseases in several species of plants, as well as having a positive effect on the photosynthetic capacity of plants. The objective of this study, was to investigate the effect of Si on the photosynthetic capacity of cotton plants of cultivars BRS Araçá and FM 993 infected by Colletotrichum gossypii var. cephalosporioides and supplied with (+Si) or not (-Si) silicon. Been evaluated variables of gas exchange: carbon assimilation rate $(A)$, stomatal conductance $\left(g_{s}\right)$, transpiration $(E)$, ratio between the concentration and $\mathrm{CO}_{2}$ environment internal $\left(C_{\mathrm{i}} / C_{\mathrm{a}}\right)$, efficiency of water use $(A / E)$ and pigment concentration. There were reduction of $A$, the gs, carbon fixation, chlorophyll a concentrations $\left(\mathrm{cl}_{\mathrm{a}}\right)$, chlorophyll $\mathrm{b}\left(\mathrm{cl} \mathrm{b}_{\mathrm{b}}\right)$ and carotenoids, total dry matter (MST) and increasing of $\mathrm{E}$. The supply of the two cotton cultivars due to increase in $g_{5}$ and $\mathrm{CO}_{2}$ fixation. The supply increased concentrations of $\mathrm{Cl}_{a} \mathrm{Cl}_{b}$, and carotenoids and MST in both cultivars. Therefore, the Si affect the physiology of plants of cotton infected by C. gossypii var. cephalosporioides, increasing the resistance to Colletotrichum gossypii in photosynthetic capacity increments due to the concentration of pigments and in the accumulation of biomass.
\end{abstract}

Key words: Colletotrichum gossypii var. cephalosporioides, photosynthesis, gas exchange abstract. 


\section{INTRODUÇÃO}

Uma das doenças mais importantes que afetam a cultura do algodoeiro (Gossypium hirsutum L. r. latifolium Hutch) no Brasil é a ramulose, causada pelo fungo Colletotrichum gossypii var. chephalosporioides A. S. Costa (Suassuna e Coutinho, 2011). O patógeno infecta as folhas, pecíolos e o caule, provocando nanismo e o superbrotamento dos ramos. Há prejuízos para a formação das maçãs e, consequentemente, para a produçáo (Mehta et al., 2005).

Considerando que C. gossypii var. cephalosporioides é um patógeno hemibiotrófico, é na fase necrotrófica que o fungo causa substanciais modificaçôes na fisiologia do algodoeiro, devido à secreção de enzimas líticas e de toxinas não específicas. Do ponto de vista fisiológico, um dos principais danos causados pelos patógenos que atacam as folhas ocorre sobre os processos fotossintéticos (Berger et al., 2007), como as trocas gasosas e a fluorescência da clorofila. Essas têm sido consideradas indicadores úteis da atividade do aparelho fotossintético em plantas sob condiçôes de estresse, como o causado por patógenos (Berger et al., 2007; Lichtenthaler e Miehé, 1997). Vários estudos têm demonstrado que a infecção por patógenos leva a uma diminuiçáo da fotossíntese (Bastiaans, 1993; Berger et al., 2007) e a modificaçóes no aparelho fotossintético (Lichtenthaler e Miehé, 1997).

Mudanças nos parâmetros fotossintéticos de Eucalyptus globulus em resposta à infecçáo por Mycosphaerella sp. tiveram uma relação linear negativa entre luz saturada e taxa de assimilação líquida de $\mathrm{CO}_{2}(A)$, a nível de folha, e os danos causados devidos à infecçáo. Reduçóes em $A$ foram proporcionalmente maiores do que o esperado pela redução na área foliar fotossinteticamente ativa, sugerindo que os tecidos assintomáticos também foram afetados pela infecção. Mudanças na abertura estomática, nas reações bioquímicas, no número e estrutura dos cloroplastos, na secreção de enzimas líticas e enzimas em tecidos assintomáticos ocorrem em plantas atacadas por patógeno (Pinkard e Mohammed, 2006). Alves et al. (2011) estudaram o efeito da infecção por Puccinia psidii sobre as trocas gasosas em Eucalyptus urophylla. Esses autores observaram que as trocas gasosas e a fluorescência da clorofila a permaneceram praticamente inalteradas em um clone resistente, enquanto no clone suscetível as taxas fotossintéticas foram afetadas principalmente por limitaçóes bioquímicas na fixação do carbono.

A concentração de pigmentos nas folhas e a integridade da membrana são cruciais para a manutençáo da $A$ em plantas (Matsuda et al., 2004). Redução na concentração de pigmentos nas folhas causada por vários patógenos como Exsorohilum turcicum em milho (Chauhan et al., 1997) e Bipolaris sorokiniana em Poa pratiensis (Hodges e Campbell, 1999) ocasionaram redução na taxa fotossintética.

Tem sido relatado que aplicaçóes do elemento Si podem reduzir a intensidade de várias doenças (Ranganathan et al., 2006; Rodrigues et al., 2003), a toxidez de alguns metais pesados, como boro e manganês (Feng et al., 2009; Gunes et al., 2007; Hodson e Sangster, 2002) e o estresse salino (Gong et al., 2003; Liang et al., 2006). Em arroz, o Si diminuiu a transpiração e a taxa da permeabilidade das membranas das plantas sob déficit hídrico (Agarie et al., 1998). Em sorgo sob déficit hídrico, a aplicação de Si aumentou o conteúdo relativo de água e o peso da matéria seca das plantas (Hattori et al., 2005). O aumento na tolerância à seca pela adiçáo de $\mathrm{Si}$ esteve associado com o aumento na capacidade de absorçáo de água. O suprimento de $\mathrm{Si}$ às plantas de trigo melhorou o status hídrico e aumentou a massa seca das plantas (Gong et al., 2003). O aumento na tolerância das plantas de trigo à seca mediado pelo Si foi devido ao aumento na capacidade da defesa antioxidante e à redução de danos oxidativos (Gong et al., 2003).

Assim, o objetivo deste estudo foi investigar o efeito do $\mathrm{Si}$ sobre a capacidade fotossintética de plantas de algodoeiro das cultivares BRS Araçá e FM 993 infectadas por Colletotrichum gossypii var. cephalosporioides e supridas $(+\mathrm{Si})$ ou não $(-\mathrm{Si})$ com Si.

\section{MATERIAL E MÉTODOS}

\section{Preparo da solução nutritiva e crescimento das plantas de algodoeiro}

Sementes de algodão das cultivares BRS Araçá e Fiber Max 993 (FM 993) foram lavadas em solução de hipoclorito de sódio $(10 \%)$ por dois minutos, seguidas de lavagem em água destilada por três minutos e germinadas em leito de areia lavada e autoclavada. Dez dias após a germinação, cinco plântulas foram transferidas para vasos plásticos contendo $5 \mathrm{~L}$ de solução nutritiva de Hoagland e Arnon (1950) modificada, constituída de: $6,0 \mathrm{mmol} \mathrm{L}-1 \mathrm{KNO}_{3}$; $1,0 \mathrm{mmol} \mathrm{L}-1 \mathrm{NH}_{4} \mathrm{H}_{2} \mathrm{PO}_{4} ; 2,0 \mathrm{mmol} \mathrm{L}-1 \mathrm{MgSO}_{4} .7 \mathrm{H}_{2} \mathrm{O}$; $4,0 \mathrm{mmol} \mathrm{L}-1 \mathrm{Ca}\left(\mathrm{NO}_{3}\right)_{2} ; 0,3 \mu \mathrm{mol} \mathrm{L}-1 \mathrm{CuSO}_{4} \cdot 5 \mathrm{H}_{2} \mathrm{O} ; 1,3$ $\mu \mathrm{mol} \mathrm{L}-1 \mathrm{ZnSO}_{4} .7 \mathrm{H}_{2} \mathrm{O} ; 46 \mu \mathrm{mol} \mathrm{L}^{-1} \mathrm{H}_{3} \mathrm{BO}_{3} ; 12,6 \mu \mathrm{mol} \mathrm{L}{ }^{-1}$ $\mathrm{MnCl}_{2} .4 \mathrm{H}_{2} \mathrm{O} ; 0,1 \mu \mathrm{mol} \mathrm{L}-1\left(\mathrm{NH}_{4}\right)_{6} \mathrm{Mo}_{7} \mathrm{O}_{24} .4 \mathrm{H}_{2} \mathrm{O} ; 45 \mu \mathrm{mol}$ $\mathrm{L}^{-1} \mathrm{FeSO}_{4} .7 \mathrm{H}_{2} \mathrm{O}$-EDTA bissódico. O ácido monossilícico obtido pela passagem do silicato de potássio através de uma coluna contendo resina trocadora de cátions (Amberlite IRA 410) (Ma e Takahashi, 2002) foi adicionado à solução nutritiva nas concentraçóes de 0 (-Si) e $2 \mathrm{mmol} \mathrm{Si} \mathrm{L}^{-1}(+\mathrm{Si})$. Foi utilizada solução nutritiva a meia força iônica incluindo a adição ou não do ácido monossilícico. Após sete dias, a concentração da solução utilizada foi modificada para força total. A solução nutritiva foi aerada, trocada a cada quatro dias e o $\mathrm{pH}$ foi verificado diariamente e mantido entre 5,5 e 6,0.

\section{Obtenção do inóculo de C. gossypii var. cephalosporioides e inoculação das plantas}

As plantas de algodoeiro foram inoculadas com o isolado CNPA 0053 de C. gossypii var. cephalosporioides fornecido pela Embrapa - Centro Nacional de Pesquisa do Algodão. O 
isolado de C. gossypii var. cephalosporioides foi armazenado em tubos de ensaio contendo meio batata-dextrose-ágar (BDA). $\mathrm{O}$ isolado foi repicado para placas de Petri contendo meio $\mathrm{BDA}$ e as placas foram transferidas para câmara de crescimento tipo B.O.D. com fotoperíodo de $12 \mathrm{~h}$ e temperatura de $25^{\circ} \mathrm{C}$ na qual permaneceram por até 15 dias até ocorrer abundante produção de conídios. O inóculo foi preparado adicionando-se $10 \mathrm{~mL}$ de água destilada em cada placa, que em seguida, foram raspadas superficialmente com pincel de cerdas macias para liberação dos conídios. A suspensão obtida foi filtrada em gaze e ajustada para a concentração de $1,5 \times 10^{6}$ conídios $/ \mathrm{mL}$. Para aumentar a aderência dos conídios ao tecido da planta, a suspensão foi preparada utilizando-se água contendo gelatina a $1 \%$ (p:v), além da adição de Tween $20(0,1 \mathrm{~mL} / 100 \mathrm{~mL}$ de suspensão) para quebrar e tensão superficial da água.

Plantas de algodoeiro no estádio V5 (40 dias após transplantio) (Marur e Ruano, 2001) foram inoculadas com C. gossypii var. cephalosporioides utilizando-se atomizador (VLS-Set Airbrush, Paache Airbrush Company, USA). Após a inoculação, as plantas foram transferidas para câmara de nevoeiro com temperatura de $25 \pm 2{ }^{\circ} \mathrm{C}$ e umidade relativa de $90 \pm 5 \%$ com fluxo contínuo de luz por $24 \mathrm{~h}$ e, em seguida, transferidas para câmara de crescimento com temperatura entre $25^{\circ} \mathrm{C}$ e $35^{\circ} \mathrm{C}$ e umidade relativa de $50 \pm 5 \%$, na qual permaneceram até o final das avaliaçóes.

\section{Avaliação da severidade}

A severidade da ramulose foi avaliada utilizando-se a escala de notas proposta por Costa e Fraga Júnior (1937) em que: $0=$ plantas sem sintomas; $1=$ plantas apresentando lesóes necróticas nas folhas, pecíolos e nervuras; $2=$ morte do ápice, hiperplasia e morte dos meristemas laterais; $3=$ encurtamento dos internódios e início do superbrotamento; e $4=$ intenso superbrotamento e redução do porte e desenvolvimento da planta, morte das partes afetadas. A severidade foi avaliada aos 10, 20 e 30 dias após inoculação (dai). As notas de severidade foram usadas para calcular o índice da ramulose (IR) de acordo com o índice de Mckinney (1923) em que: $\mathrm{IR}=[$ (nota da doença×número de plantas com essa nota)/ (número total de plantas $\times$ nota máxima da doença na escala) $] \times 100$. Os valores do IR para as repetições de cada tratamento foram utilizados para calcular a área abaixo da curva do índice da ramulose (AACIR) de acordo com a fórmula proposta por Shaner e Finney (1977).

\section{Determinação dos parâmetros de trocas gasosas}

A taxa de assimilação líquida de carbono $(A)$, a condutância estomática $(g)$, a transpiração $(E)$, a razão entre a concentração interna e ambiente de $\mathrm{CO}_{2}\left(C_{\mathrm{i}} / C_{\mathrm{a}}\right)$ e a eficiência instantânea do uso da água $(A / E)$ foram determinadas na quarta folha do ápice para a base, em uma planta que se encontrava no estádio V5 (Marur e Ruano, 2001), por repetiçáo de cada parcela. As avaliaçôes foram realizadas entre as 08:00 e 11:00 hs, em sistema aberto, sob irradiância de saturaçáo de $1000 \mu \mathrm{mol}$ $\mathrm{m}^{-2} \mathrm{~s}^{-1}$, utilizando-se um analisador de gases infravermelho (LC pro+, Analytical Development Company, Hoddesdon, Reino Unido). Durante as avaliaçóes, a umidade relativa do ar foi de $\approx 80 \pm 5 \%$, a temperatura foliar variou de $28{ }^{\circ} \mathrm{C}$ a $33{ }^{\circ} \mathrm{C}$ e a concentraçáo ambiente de $\mathrm{CO}_{2}$ foi cerca de $380 \mu \mathrm{mol} \mathrm{mol}^{-1}$. Para permitir a ativaçáo plena da atividade da maquinaria fotossintética, as plantas foram mantidas cerca de meia hora fora da câmara de nebulização, a pleno sol, antes das avaliaçóes. As avaliaçóes foram realizadas aos 5 , 10, 20 e 30 dias após inoculaçấo (dai) em uma planta por repetição de cada tratamento. As avaliaçóes também foram realizadas nas plantas náo inoculadas com $C$. gossypii var. cephalosporioides $(0 \mathrm{~h})$.

\section{Determinação da concentração de pigmentos}

Para a determinação da concentração dos pigmentos nas folhas, amostras de $100 \mathrm{mg}$ da quarta folha das plantas de cada repetição foram coletadas aos $0,10,20$ e 30 dai. As amostras foram maceradas em nitrogênio $\left(\mathrm{N}_{2}\right)$ líquido contendo 0,01 $\mathrm{g}$ de carbonato de cálcio e, em seguida, homogeneizadas com $2 \mathrm{~mL}$ de acetona $80 \%(\mathrm{v} / \mathrm{v})$ por $1 \mathrm{~min}$ sob luz verde. A suspensão resultante foi filtrada em papel filtro Whatman \# 1. O resíduo foi lavado três vezes em acetona a $80 \%$ e o volume final completado em baláo volumétrico para $25 \mathrm{~mL}$, com o mesmo solvente. As absorbâncias dos extratos foram lidas em espectrofotômetro (Evolution 60, Thermo Scientific, Waltham, MA, EUA) nos comprimentos de onda 470, 646,8 e $663,2 \mathrm{~nm}$. As concentraçóes de clorofila a $\left(\mathrm{Cl}_{\mathrm{a}}\right)$, clorofila $\mathrm{b}\left(\mathrm{Cl}_{\mathrm{b}}\right)$ e carotenoides e pigmentos totais foram estimadas de acordo com Lichtenthaler (1987).

\section{Massa seca e razões alométricas}

Foram realizadas análises destrutivas das plantas inoculadas e não inoculadas com C. gossypii var. cephalosporioides de cada cultivar aos 30 dai. As plantas foram separadas em limbo foliar, pecíolos, caule e raízes. A área das folhas de cada planta foi obtida com o equipamento medidor de área foliar LiCor 3100 (LI-COR Inc., Lincoln, NE, USA). Todas as partes da planta foram secadas em estufa com ventilação forçada de ar a $70^{\circ} \mathrm{C}$ até atingirem massa constante sendo, em seguida, pesadas.

Com os valores de biomassa seca, foram obtidas as seguintes variáveis, de acordo com Hunt (1990):

a) Matéria Seca Total (MST): somatório da matéria seca de todas as partes da planta; 
b) Razão de Massa Foliar (RMF): razão entre a biomassa seca alocada para a folha em relação à biomassa total $\left(\mathrm{RMF}=\mathrm{W}_{\text {folha }} / \mathrm{W}_{\text {total }}\right)$;

c) Razão de Massa Caulinar (RMC): razão entre a biomassa seca alocada no caule em relação à biomassa total $\left(\mathrm{RMC}=\mathrm{W}_{\text {caule }} / \mathrm{W}_{\text {total }}\right)$;

d) Razão de Massa Radicular (RMR): razão entre a biomassa seca alocada na raiz em relação à biomassa total $\left(\mathrm{RMR}=\mathrm{W}_{\text {raiz }} / \mathrm{W}_{\text {total }}\right)$;

e) Razão de Massa do Pecíolo (RMP): razão entre a biomassa seca alocada no pecíolo em relação à biomassa total $\left(\mathrm{RMP}=\mathrm{W}_{\text {pecíolo }} / \mathrm{W}_{\text {total }}\right)$;

f) Área Foliar Específica $\left(\mathrm{AFE}-\mathrm{m}^{2} \mathrm{~kg}^{-1}\right)$ : trata-se da razão entre a área da folha em relação a massa da folha (AFE $=\mathrm{L} /$ $\left.\mathrm{W}_{\text {folha }}\right)$;

g) Razão de Área Foliar $\left(\mathrm{RAF}-\mathrm{m}^{2} \mathrm{~kg}^{-1}\right)$ : trata-se da razão entre a área da folha em relação a massa seca total da planta $\left(\mathrm{RAF}=\mathrm{L}_{\mathrm{a}} / \mathrm{W}_{\text {planta }}\right)$.

\section{Determinação da concentração foliar de Si}

Aos 30 dai, as folhas das plantas das repetiçóes dos tratamentos foram coletadas, lavadas em água destilada e secadas em estufa com ventilação forçada de ar a $70{ }^{\circ} \mathrm{C}$ até atingirem massa constante. Posteriormente, as folhas foram moídas em moinho tipo Thomas-Wiley (Thomas Scientific, Swedesboro, NJ), equipado com peneira de 20 mesh $(0,84 \mathrm{~mm})$, para determinaçáo da concentração foliar de Si conforme proposto por Korndörfer et al. (2004).

\section{Delineamento experimental e análise estatística dos dados}

Foi conduzido um experimento instalado em delineamento em blocos casualizados em esquema fatorial $2 \times 2 \times 2$, com dez repetiçóes. Os fatores estudados foram duas cultivares de algodoeiro, duas formas de inoculação (plantas não inoculadas e inoculadas) e supridas $(+\mathrm{Si})$ ou não $(-\mathrm{Si})$ com Si. Foram utilizadas dez repetiçóes para avaliação de trocas gasosas, análise de crescimento, severidade e análise foliar de Si; para pigmentos, foram utilizadas apenas quatro repetiçóes. Cada unidade experimental foi composta por um vaso plástico contendo cinco plantas de algodão. Os dados obtidos para cada variável foram submetidos à análise de variância (ANOVA) e as médias dos tratamentos comparadas pelo test- $t(\mathrm{p} \leq 0,05)$ ou pelo teste Tukey $(\mathrm{p} \leq 0,05)$ utilizando-se o SAS versão 6.12. O índice de ramulose foi correlacionado com as médias obtidas para as variáveis fotossintéticas e as variáveis fotossintéticas foram correlacionadas entre si.

\section{RESULTADOS}

\section{Índice da ramulose e concentração foliar de Si}

Os valores do índice da ramulose nas plantas de algodoeiro das duas cultivares supridas com Si foram menores em relação aos obtidos paras as plantas das duas cultivares não supridas com esse elemento. Houve interação significativa entre os fatores cultivares $\times$ doses de Si para a AACIR e para a concentração foliar de Si (Tabela 1).

\section{Trocas gasosas}

Houve efeito significativo da inoculação paras as variáveis $A, g_{s}, C / C$, e $A / E$. Houve efeito significativo da cultivar para a variável $E$ e efeito da dose de Si para todas as variáveis avaliadas (Tabela 2). A interação entre os fatores cultivares $\times$ inoculação foi significativa para a variável $E$ (Tabela 3 ) e a interação entre os fatores inoculação $\times$ doses de Si foi significativa para a variável $C_{i} / C_{a}$ (Tabela 4).

Nas plantas da cultivar BRS Araçá não inoculadas e supridas com $\mathrm{Si}$ ocorreram aumentos significativos em $A$ aos 20 e 30 dai (Figura 1a), e, aos 10 dai, em $A / E_{\mathrm{i}}$ (Figura 2a),

Tabela 1. Área abaixo da curva do índice da ramulose (AACIR) e concentraçáo foliar de silício (Si) (g/kg) em plantas de algodão das cultivares BRS Araçá e FM 993 crescidas em soluçáo nutritiva contendo (+Si) ou náo (-Si) silício e inoculadas com Colletotrichum gossypii var. cephalosporioides ou não

\begin{tabular}{|c|c|c|c|c|c|}
\hline \multicolumn{2}{|c|}{ Cultivares } & \multicolumn{2}{|c|}{ AACIR } & \multicolumn{2}{|c|}{ Si (g/kg) } \\
\hline & & BRS Araçá & FM 993 & BRS Araçá & FM 993 \\
\hline \multirow{2}{*}{ Silício } & $-\mathrm{Si}$ & $1325 \mathrm{Ab}$ & $1900 \mathrm{Aa}$ & 0,70 Ba & 0,90 Ba \\
\hline & $+\mathrm{Si}$ & $1050 \mathrm{Bb}$ & $1287 \mathrm{Ba}$ & $12,20 \mathrm{Aa}$ & $8,10 \mathrm{Ab}$ \\
\hline Valores de F & & \multicolumn{2}{|c|}{ AACIR } & \multicolumn{2}{|c|}{$\mathrm{Si}$} \\
\hline Cultivares (C) & & \multicolumn{2}{|c|}{$36,38^{*}$} & \multicolumn{2}{|c|}{$3,96^{\text {ns }}$} \\
\hline Silício (Si) & & \multicolumn{2}{|c|}{$43,41^{*}$} & \multicolumn{2}{|c|}{$89,76^{*}$} \\
\hline $\mathrm{C} \times \mathrm{Si}$ & & \multicolumn{2}{|c|}{$6,25^{*}$} & \multicolumn{2}{|c|}{$4,67^{*}$} \\
\hline CV (\%) & & \multicolumn{2}{|c|}{15,31} & \multicolumn{2}{|c|}{36,64} \\
\hline
\end{tabular}

${ }^{*} \mathrm{p} \leq 0,05$ : significativo a $5 \%$ de significância pelo teste- $F$; ${ }^{\text {ns: }}$ náo significativo; $C V$ : coeficiente de variaçáo; médias na coluna seguidas de mesmas letras maiúsculas ou médias na linha seguidas de letras minúsculas distintas são estatisticamente diferentes $(\mathrm{p} \leq 0,05)$, de acordo com o teste de Tukey 
Tabela 2. Análise de variância para as variáveis taxa de assimilação líquida de carbono $(A)$, condutância estomática $\left(g_{s}\right)$, taxa transpiratória $(E)$, razáo entre concentraçáo interna e ambiente de $\mathrm{CO}_{2}\left(C_{\mathrm{i}} / C_{\mathrm{a}}\right)$, eficiência instantânea no uso da água $(A / E)$, concentraçáo de clorofila a $\left(\mathrm{Cl}_{\mathrm{a}}\right.$ ), clorofila $\mathrm{b}\left(\mathrm{Cl}_{\mathrm{b}}\right)$, carotenoides (Carot) e pigmentos totais (Pigm. totais) em folhas de plantas de algodoeiro das cultivares BRS Araçá e FM 993 crescidas em solução nutritiva contendo $(+\mathrm{Si})$ ou não $(-\mathrm{Si})$ silício, inoculadas com Colletotrichum gossypii var. cephalosporioides ou não

\begin{tabular}{|c|c|c|c|c|c|c|c|c|c|c|}
\hline Fontes c & le variação & $A$ & $g_{s}$ & $E$ & $C_{i} / C_{a}$ & $A / E$ & $\mathrm{Cl}_{\mathrm{a}}$ & $\mathrm{Cl}_{\mathrm{b}}$ & Carot & $\begin{array}{l}\text { Pigm. } \\
\text { totais }\end{array}$ \\
\hline \multirow{3}{*}{ Cultivares } & BRS Araçá & 23,21 & 0,32 & 3,91 & 0,55 & 0,101 & 44,24 & 16,36 & 10,71 & 5,70 \\
\hline & FM 993 & 22,42 & 0,31 & 4,22 & 0,55 & 0,090 & 47,32 & 15,73 & 10,82 & 5,96 \\
\hline & DMS & $0,88^{\text {ns }}$ & $0,02^{\text {ns }}$ & $0,13^{*}$ & $0,02^{\text {ns }}$ & $0,005^{\mathrm{ns}}$ & $2,34^{*}$ & $0,91^{\text {ns }}$ & $0,61^{\text {ns }}$ & $0,26^{\text {ns }}$ \\
\hline \multirow{3}{*}{ Inoculação } & Plantas não inoculadas & 25,62 & 0,37 & 4,12 & 0,51 & 0,112 & 45,00 & 15,44 & 11,07 & 6,12 \\
\hline & Plantas inoculadas & 20,02 & 0,26 & 3,99 & 0,59 & 0,084 & 46,56 & 16,65 & 10,46 & 5,53 \\
\hline & DMS & $0,88^{*}$ & $0,02^{*}$ & $0,13^{\text {ns }}$ & $0,02^{*}$ & $0,005^{*}$ & $2,34^{\mathrm{ns}}$ & $0,91^{*}$ & $0,61^{\text {ns }}$ & $0,26^{\text {ns }}$ \\
\hline \multirow{3}{*}{ Silício } & $-\mathrm{Si}$ & 22,21 & 0,30 & 4,27 & 0,57 & 0,095 & 44,42 & 15,70 & 10,19 & 5,99 \\
\hline & $+\mathrm{Si}$ & 23,43 & 0,34 & 3,84 & 0,53 & 0,102 & 47,14 & 16,38 & 11,35 & 5,67 \\
\hline & DMS & $0,08^{*}$ & $0,02^{*}$ & $0,13^{*}$ & $0,02^{*}$ & $0,005^{*}$ & $2,34^{*}$ & $0,91^{\mathrm{ns}}$ & $0,61^{*}$ & $0,26^{*}$ \\
\hline \multicolumn{11}{|c|}{ Valores de $F$} \\
\hline Blocos & & $0,20^{\text {ns }}$ & $0,41^{\mathrm{ns}}$ & $0,22^{\text {ns }}$ & $0,13^{\text {ns }}$ & $0,21^{\text {ns }}$ & $0,16^{\mathrm{ns}}$ & $0,07^{\text {ns }}$ & $0,71^{\text {ns }}$ & $0,36^{\text {ns }}$ \\
\hline Cultivares (C) & & $3,11^{\mathrm{ns}}$ & $0,51^{\mathrm{ns}}$ & $19,04^{*}$ & $0,01^{\mathrm{ns}}$ & $3,27^{\text {ns }}$ & $6,81^{*}$ & $1,86^{\mathrm{ns}}$ & $0,14^{\text {ns }}$ & $3,54^{\text {ns }}$ \\
\hline Inoculação (I) & & $156,40^{*}$ & $108,17^{*}$ & $3,75^{\mathrm{ns}}$ & $56,28^{*}$ & $111,52^{*}$ & $1,73^{\text {ns }}$ & $6,83^{*}$ & $3,88^{\text {ns }}$ & $19,25^{*}$ \\
\hline Doses de silício (Si) & & $7,44^{*}$ & $11,13^{*}$ & $39,95^{*}$ & $18,49^{*}$ & $6,82^{*}$ & $5,28^{*}$ & $2,18^{\text {ns }}$ & $13,82^{*}$ & $6,03^{*}$ \\
\hline$C \times 1$ & & $0,61^{\text {ns }}$ & $0,34^{\text {ns }}$ & $9,40^{*}$ & $0,02^{\text {ns }}$ & $0,57^{\text {ns }}$ & $3,63^{\text {ns }}$ & $3,51^{\mathrm{ns}}$ & $3,53^{\text {ns }}$ & $0,01^{\mathrm{ns}}$ \\
\hline $\mathrm{C} \times \mathrm{Si}$ & & $0,01^{\text {ns }}$ & $0,09^{\text {ns }}$ & $1,49^{\text {ns }}$ & $3,94^{\mathrm{ns}}$ & $2,19^{\text {ns }}$ & $0,93^{\text {ns }}$ & $1,98^{\text {ns }}$ & $16,16^{\mathrm{ns}}$ & $28,89^{\text {ns }}$ \\
\hline $\mathrm{I} \times \mathrm{Si}$ & & $0,47^{\text {ns }}$ & $0,06^{\text {ns }}$ & $0,01^{\mathrm{ns}}$ & $13,83^{*}$ & $2,55^{\text {ns }}$ & $2,36^{\mathrm{ns}}$ & $0,16^{\mathrm{ns}}$ & $0,02^{\text {ns }}$ & $1,41^{\mathrm{ns}}$ \\
\hline $\mathrm{C} \times \mathrm{I} \times \mathrm{Si}$ & & $0,32^{\text {ns }}$ & $0,30^{\text {ns }}$ & $0,24^{\mathrm{ns}}$ & $0,34^{\mathrm{ns}}$ & $0,22^{\text {ns }}$ & $0,54^{\text {ns }}$ & $1,52^{\text {ns }}$ & $0,01^{\text {ns }}$ & $0,01^{\text {ns }}$ \\
\hline CV (\%) & & 15,18 & 26,12 & 13,02 & 14,62 & 20,84 & 14,61 & 16,25 & 16,40 & 13,04 \\
\hline
\end{tabular}

${ }^{*} \mathrm{p} \leq 0,05$ : significativo a $5 \%$ de significância pelo teste- $F$; ${ }^{*} \mathrm{p} \leq 0,05$ : significativo a $5 \%$ de significância pelo teste- $t$; ${ }^{\text {ns: }}$ năo significativo; CV: coeficiente de variação

Tabela 3. Taxa transpiratória $(E)\left(\mathrm{mmol} \mathrm{m} \mathrm{m}^{-2} \mathrm{~s}^{-1}\right)$ em plantas das cultivares de algodoeiro BRS Araçá e FM 993 crescidas em solução nutritiva e inoculadas com Colletotrichum gossypii var. cephalosporioides ou não

\begin{tabular}{cccc}
\multicolumn{2}{c}{ Inoculação } & $\begin{array}{c}\text { Plantas não } \\
\text { inoculadas }\end{array}$ & $\begin{array}{c}\text { Plantas } \\
\text { inoculadas }\end{array}$ \\
\multirow{2}{*}{ Cultivares } & BRS Araçá & $3,74 \mathrm{Bb}$ & $4,08 \mathrm{Aa}$ \\
& FM 993 & $4,25 \mathrm{Aa}$ & $4,17 \mathrm{Aa}$ \\
\hline
\end{tabular}

Médias na mesma linha seguidas de letras maiúsculas diferentes ou médias na mesma coluna seguidas de letras minúsculas distintas săo estatisticamente diferentes $(\mathrm{p} \leq 0,05)$ de acordo com o teste de Tukey

Tabela 4. Razão entre a concentração interna e ambiente de $\mathrm{CO}_{2}\left(C_{i} /\right.$ $C_{\mathrm{a}}$ ) em folhas de plantas de algodoeiro crescidas em soluçáo nutritiva contendo $(+\mathrm{Si})$ ou náo $(-\mathrm{Si})$ silício $(\mathrm{Si})$ e inoculadas com Colletotrichum gossypii var. cephalosporioides ou não

\begin{tabular}{|cccc} 
Inoculação & $\begin{array}{c}\text { Plantas não } \\
\text { inoculadas }\end{array}$ & $\begin{array}{c}\text { Plantas } \\
\text { inoculadas }\end{array}$ \\
\hline \multirow{2}{*}{ Silício } & $-\mathrm{Si}$ & $0,63 \mathrm{Aa}$ & $0,55 \mathrm{Ba}$ \\
& $+\mathrm{Si}$ & $0,51 \mathrm{Ab}$ & $0,51 \mathrm{Ab}$ \\
\hline
\end{tabular}

Médias na mesma linha seguidas de letras maiúsculas diferentes ou médias na mesma coluna seguidas de letras minúsculas distintas são estatisticamente diferentes $(\mathrm{p} \leq 0,05)$ de acordo com o teste de Tukey

quando comparadas às plantas do tratamento -Si. A variável $E$ nas plantas não inoculadas supridas com $\mathrm{Si}$ apresentou reduçôes significativas aos 5 e 30 dai quando comparada à das plantas não inoculadas do tratamento +Si (Figura 3a). A relação $C_{i} / C_{a}$ nas plantas não inoculadas supridas com Si reduziu-se significativamente aos 0,5 e 20 dai quando comparadas à das plantas náo inoculadas do tratamento + Si (Figura 4a).

Nas plantas da cultivar BRS Araçá inoculadas supridas com Si ocorreram aumentos significativos em $A$ aos 5, 10 e 30 dai (Figura 1b); aos 20 dai na $g_{s}$ (Figura 5b); e aos 10 e 30 dai na $A / E$ (Figura $2 \mathrm{~b}$ ), quando comparadas às das plantas inoculadas que não receberam Si. Nas plantas inoculadas supridas com Si reduziu-se significativamente a $E$ aos 10 e 30 dai, quando comparada à das plantas não inoculadas do tratamento $+\mathrm{Si}$ (Figura 3b). Nas plantas da cultivar BRS Araçá inoculadas supridas com $\mathrm{Si}$, a $C_{\mathrm{i}} / C_{\mathrm{a}}$ reduziu significativamente aos 20 e 30 dai quando comparada à das plantas não inoculadas do tratamento + Si (Figura 4b).

As plantas não inoculadas supridas com Si da cultivar FM 993 apresentaram aumentos significativos em $A$ aos 10, 20 e 30 dai (Figura 1c) e na $g_{s}$ aos 5 e 10 dai (Figura 5c) quando comparadas às das plantas não inoculadas do tratamento -Si. A variável $E$ reduziu significativamente aos 5 e 10 dai nas plantas náo inoculadas supridas com $\mathrm{Si}$, quando comparadas com a das plantas inoculadas do tratamento +Si (Figura 3c).

As plantas da cultivar FM 993 inoculadas e supridas com Si apresentaram aumentos significativos na $A$ aos 10 e 30 dai (Figura 1d), na $g_{s}$ aos 20 dai (Figura 5d) e em $A / E$ aos 10 e 30 dai (Figura 2d), quando comparadas às das plantas inoculadas e que não receberam Si. Nas plantas inoculadas que receberam $S i$, a $E$ reduziu significativamente aos 10 e 

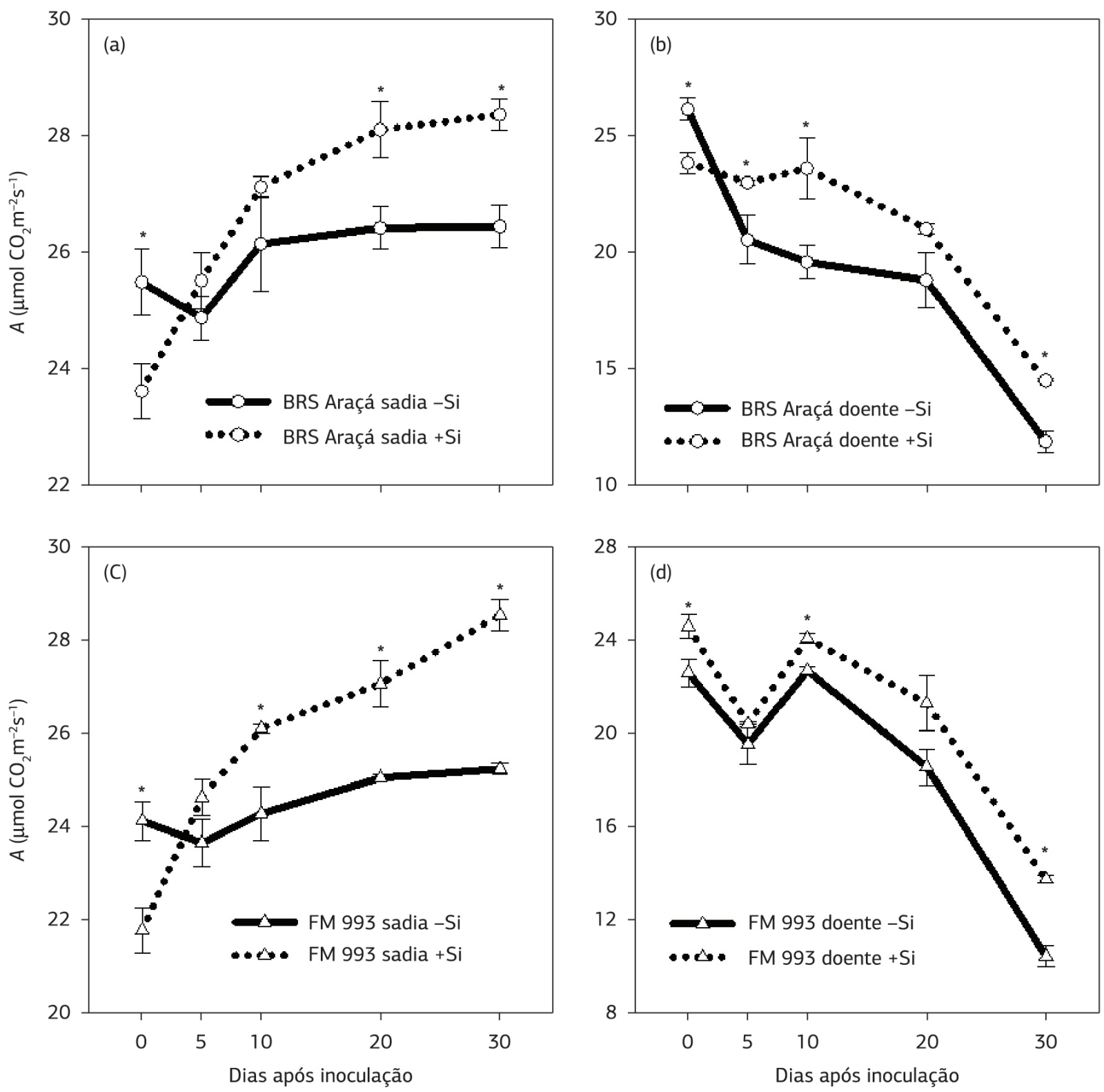

Figura 1. Taxa de assimilação líquida de carbono $(A)$ em folhas de algodoeiro das cultivares BRS Araçá (a, b) e FM 993 (c, d) crescidas em solução nutritiva contendo $(+\mathrm{Si})$ ou não $(-\mathrm{Si})$ silício $(\mathrm{Si})$, não inoculadas $(\mathrm{a}, \mathrm{c})$ e inoculadas $(\mathrm{b}, \mathrm{d})$ com Colletotrichum gossypii var. cephalosporioides; cada ponto representa a média de dez repetiçóes; barras representam o desvio padráo da média; médias entre os tratamentos -Si e $+\mathrm{Si} \mathrm{seguidas} \mathrm{de} \mathrm{asterisco}\left(^{*}\right)$ sáo significativamente diferentes pelo teste- $t$ a $5 \%$ de significância.

30 dai, quando comparada com a das plantas do tratamento $+\mathrm{Si}$ (Figura 3d). Nas plantas inoculadas supridas com $\mathrm{Si}$, a $C_{\mathrm{i}} / C_{\mathrm{a}}$ reduziu-se significativamente aos 10,20 e 30 dai, quando comparada à das plantas inoculadas do tratamento -Si (Figura 4d).

\section{Concentração de pigmentos}

Houve efeitos significativos: do fator cultivares para a variável concentração de $c l_{\mathrm{a}}$, do fator inoculação para as variáveis concentração de $c l_{\mathrm{b}}$ e do fator doses de Si para as variáveis concentração de $c l$, carotenoides e pigmentos totais (Tabela 2).

As plantas da cultivar BRS Araçá inoculadas do tratamento +Si apresentaram aumentos significativos na concentração de $c l_{\mathrm{a}}$ aos 30 dai (Figura 6b), na concentraçáo de $c l_{\mathrm{b}}$ aos 20 dai (Figura 6b) e nos pigmentos totais aos 30 dai (Figura $7 \mathrm{~b}$ ) quando comparados aos das plantas inoculadas do tratamento $-\mathrm{Si}$.

Nas plantas da cultivar FM 993 inoculadas do tratamento +Si houve aumentos significativos na concentração de $c_{\mathrm{a}}$ aos 20 e 30 dai (Figura 6d), na concentração de $c_{\mathrm{b}}$ aos 10 e 20 dai (Figura 6d), na concentraçấo de carotenoides aos 

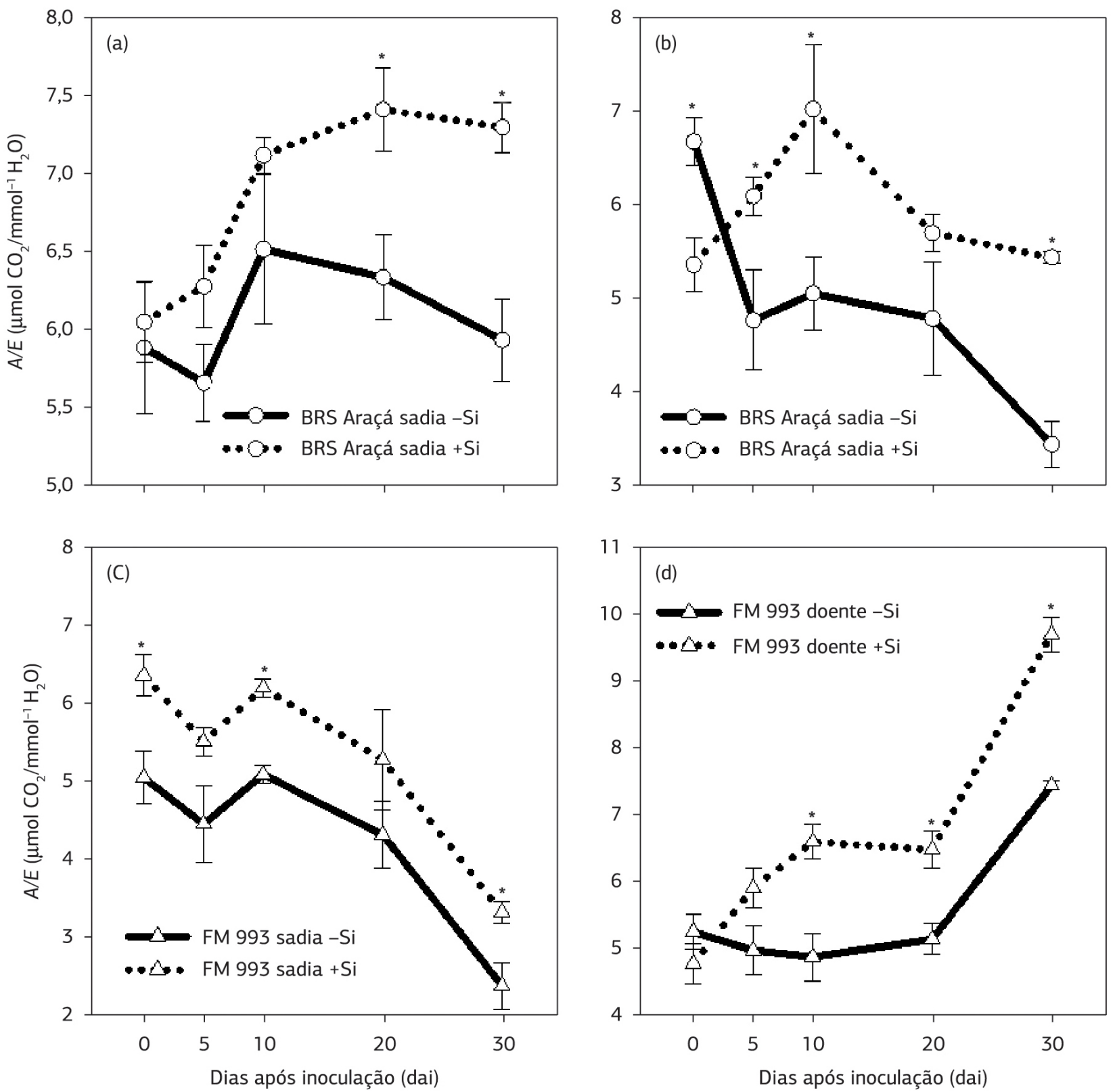

Figura 2. Eficiência instantânea no uso da água $(A / E$ - razão entre a taxa de assimilaçáo líquida de carbono e a taxa de transpiração de água) determinada em folhas de algodoeiro das cultivares BRS Araçá (a e b) e FM 993 (c, d) crescidas em soluçáo nutritiva contendo (+Si) ou não $(-\mathrm{Si})$ silício $(\mathrm{Si})$, não inoculadas $(\mathrm{a}, \mathrm{c})$ e inoculadas $(\mathrm{b}, \mathrm{d})$ com Colletotrichum gossypii var. cephalosporioides; cada ponto representa a média de dez repetiçôes. barras representam o desvio padrão da média; médias entre os tratamentos -Si e +Si seguidas de asterisco $\left(^{*}\right)$ são significativamente diferentes pelo teste- $t$ a $5 \%$ de significância.

10 e 30 dai (Figura 7d), quando comparadas às das plantas inoculadas do tratamento $-\mathrm{Si}$.

\section{Razões alométricas}

Houve efeito significativo do fator cultivares para as variáveis RMF, RMC, RMR, AFE e RAF (Tabela 5). Foi constatado efeito significativo do fator inoculação para as variáveis MST, RMF, RMC, RMR e RAF (Tabela 5). Houve efeito significativo do fator doses de $\mathrm{Si}$ para as variáveis MST, RMF, RMP, AFE e RAF (Tabela 5). A interação entre os fatores cultivares $\times$ inoculação foi significativa para as variáveis MST e RMR (Tabelas 5 e 6).

\section{Correlação de Pearson}

Nas plantas supridas com Si houve correlaçáo negativa significativa entre o IR e as variáveis $A, g_{s}, E, A / E$ e MST e correlação positiva significativa entre IR e $C_{i} / C_{a}$. Observou-se também correlaçôes positivas significativas entre as variáveis $A$ e $g_{\mathrm{s}}$, entre as variáveis A e MST e entre as variáveis $g_{\mathrm{s}} \mathrm{e}$ $E$ (Tabela 7). 

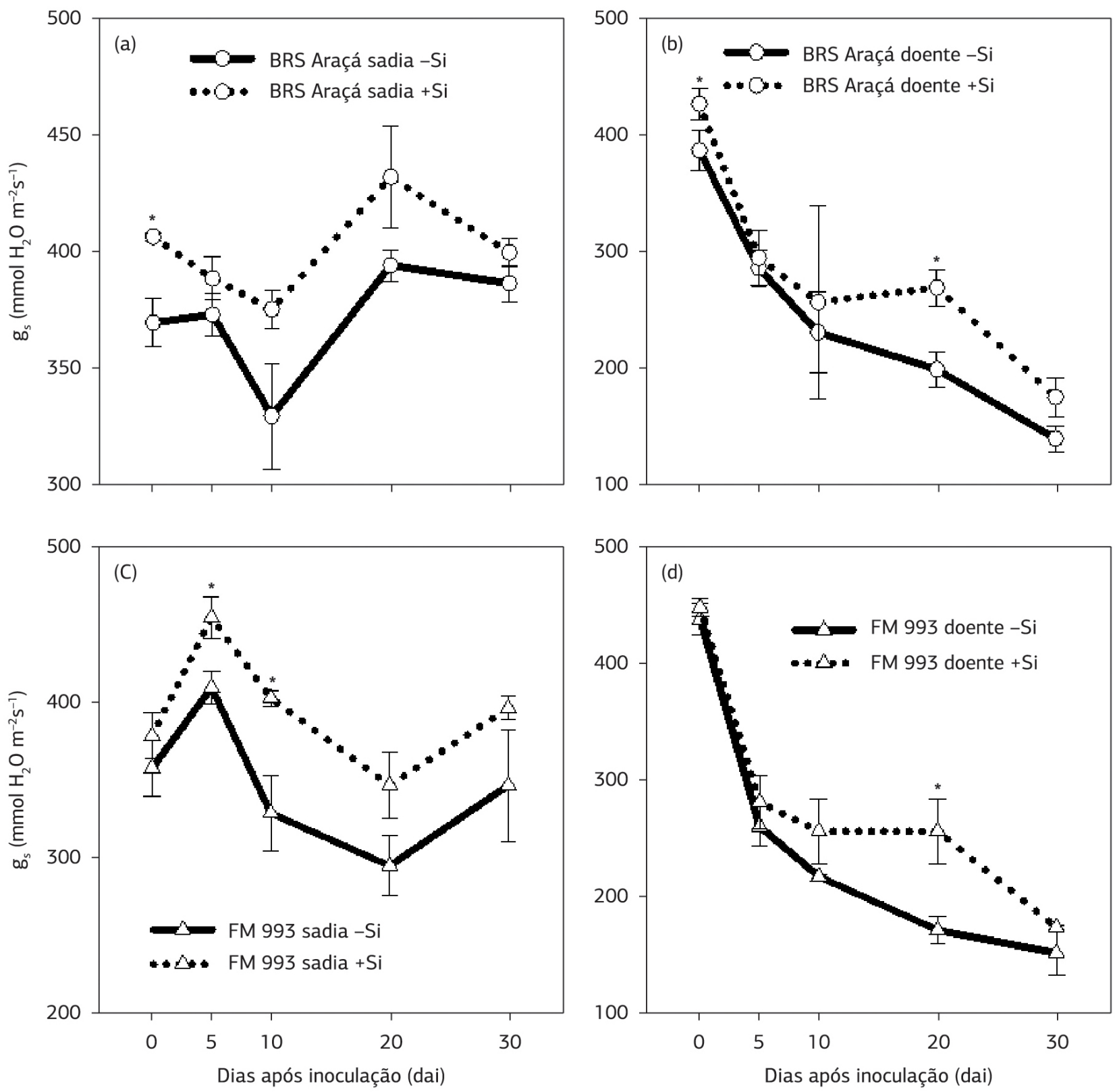

Figura 3. Taxa de transpiração $(E)$ determinada em folhas de algodoeiro das cultivares BRS Araçá (a, b) e FM 993 (c, d) crescidas em soluçâo nutritiva contendo $(+\mathrm{Si})$ ou não $(-\mathrm{Si})$ silício $(\mathrm{Si})$, não inoculadas $(\mathrm{a}, \mathrm{c})$ e inoculadas $(\mathrm{b}, \mathrm{d})$ com Colletotrichum gossypii var. cephalosporioides; cada ponto representa a média de dez repetiçóes; barras representam o desvio padrão da média; médias entre os tratamentos -Si e +Si seguidas de asterisco $\left({ }^{*}\right)$ são significativamente diferentes pelo teste- $t$ a $5 \%$ de significância.

\section{DISCUSSÃO}

Todas as variáveis das trocas gasosas nas duas cultivares foram afetados negativamente após a inoculação com $C$. gossypii var. cephalosporioides, fato confirmado através da AACIR, sendo esses efeitos mais intensos a partir dos 10 dai, período posterior à incubação de C. gossypii var. cephalosporioides. Com isso, é possível propor que a extensão do IR pode ser um bom indicador do potencial de impacto da doença sobre a assimilação de $\mathrm{CO}_{2}$, fato confirmado a partir das correlaçóes obtidas entre IR e as variáveis fotossintéticas avaliadas. Na maioria das doenças foliares, a $A$ é reduzida a partir do início da infecção (Berger et al., 2007), sendo uma menor $g_{s}$ uma das principais restriçôes para a fotossíntese nas plantas doentes. A redução na $g_{\mathrm{s}}$ limita o influxo de $\mathrm{CO}_{2}$ às folhas (Dallagnol et al., 2011). Nas folhas de plantas infectadas por diferentes patógenos, observa-se que, geralmente, ocorre uma redução no transporte de elétrons da cadeia fotossintética, indicando decréscimo na eficiência do uso da luz e, consequentemente, um aumento 

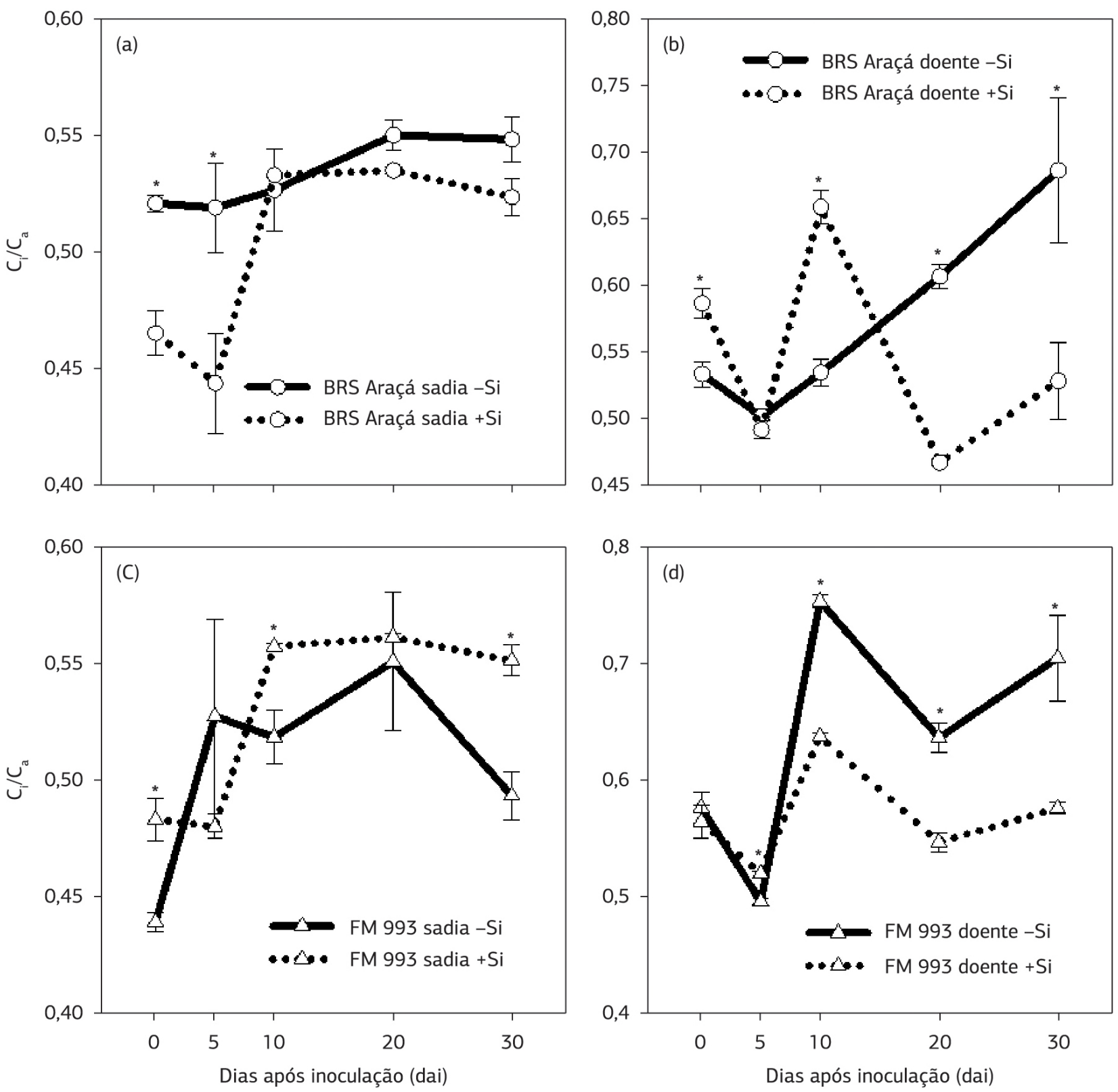

Figura 4. Razão entre a concentração interna e concentraçấo externa de $\mathrm{CO}_{2}\left(C_{\mathrm{i}} / C_{\mathrm{a}}\right)$ determinada em folhas de algodoeiro das cultivares BRS Araçá (a, b) e FM 993 (c, d) crescidas em solução nutritiva contendo (+Si) ou não (-Si) silício ( $\mathrm{Si}$ ), não inoculadas (a, c) e inoculadas (b, d) com Colletotrichum gossypii var. cephalosporioides; cada ponto representa a média de dez repetiçóes; barras representam o desvio padrão da média; médias entre os tratamentos $-\mathrm{Si}$ e $+\mathrm{Si}$ seguidas de asterisco $\left(^{*}\right)$ são significativamente diferentes pelo teste- $t$ a $5 \%$ de significância.

no excesso de energia de excitação. Essa energia em excesso pode estar associada com o decréscimo na $g_{s}$, criando, assim, condiçôes para elevar a produção de EROs que prejudicam a homeostase celular (Mateo et al., 2004).

É possível que a atividade das enzimas envolvidas na fixação do $\mathrm{CO}_{2}$ tenha sido afetada, pois foram constatados elevados valores de $C_{\mathrm{i}} / C_{\mathrm{a}}$. A reduçáo na transpiraçáo nas plantas doentes pode estar relacionada com a destruiçáo da cutícula e dos estômatos e o rompimento do limbo foliar, conduzindo diretamente a reduçóes na $g s$, já que nessas plantas a AACIR foi maior quando comparada com a das plantas supridas com Si. Isso corrobora com constataçóes de Bastiaans (1993), em que a infecção por Magnaporthe grisea em arroz reduziu a fotossíntese devido à diminuição da área foliar verde ao redor das lesóes. Em folhas de trigo infectadas por Puccinia coronata, a fotossíntese foi severamente inibida, indicando que o aparelho fotossintético foi severamente danificado (Scholes e Rolfe, 1996). Laranjeiras infectadas por Xylella fastidiosa mostraram diminuiçáo na assimilação de $\mathrm{CO}_{2}$ causada pela baixa $g_{s}$, bem como por limitaçóes bioquímicas à maquinaria fotossintética (Ribeiro et al., 2003). Resultados semelhantes foram relatados para plantas 

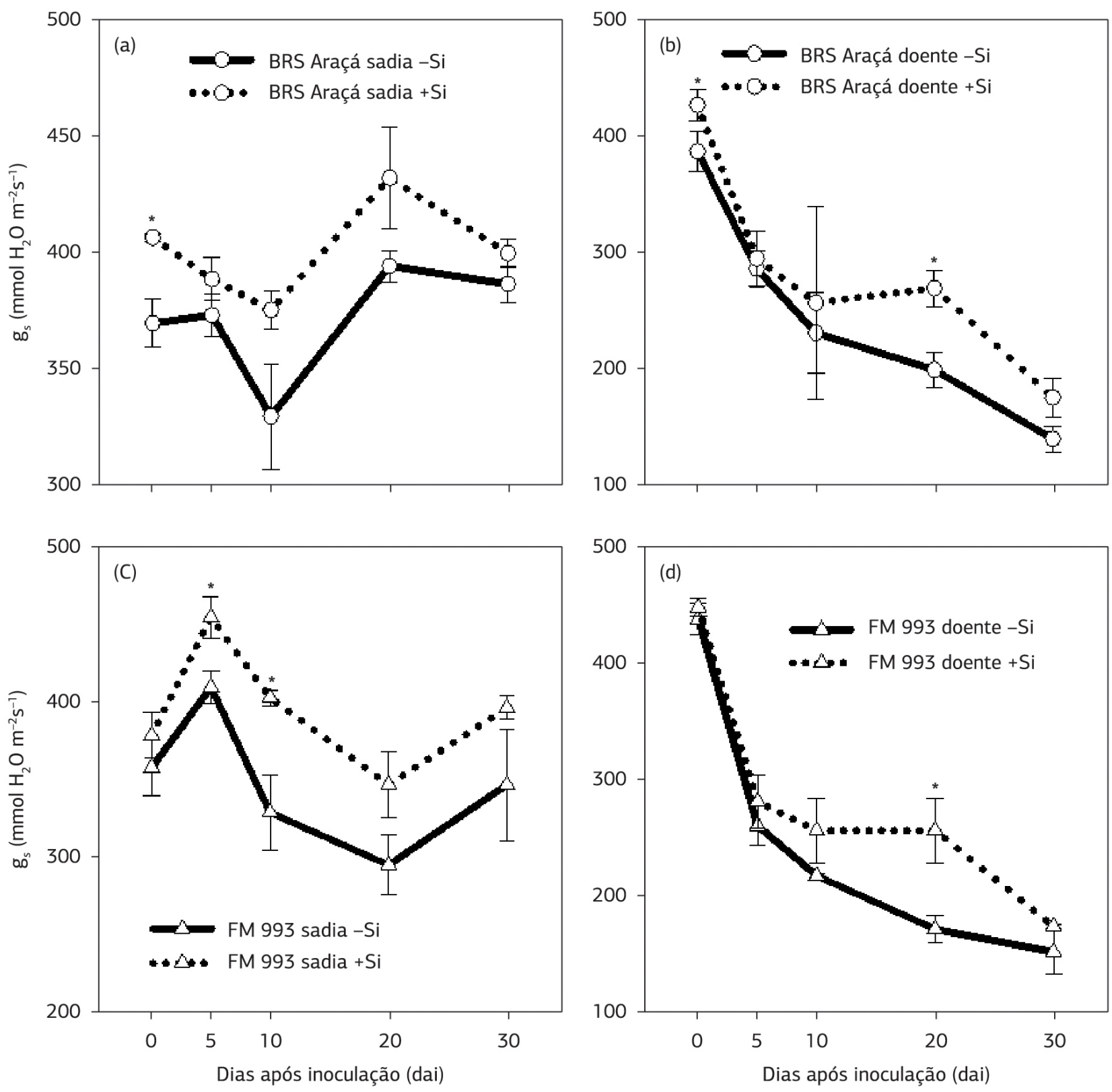

Figura 5. Condutância estomática $\left(g_{s}\right)$ determinada em folhas de algodoeiro das cultivares BRS Araçá (a, b) e FM 993 (c, d) crescidas em solução nutritiva contendo $(+\mathrm{Si})$ ou não $(-\mathrm{Si})$ silício $(\mathrm{Si})$, não inoculadas $(\mathrm{a}, \mathrm{c})$ e inoculadas $(\mathrm{b}, \mathrm{d})$ com Colletotrichum gossypii var. cephalosporioides; cada ponto representa a média de dez repetiçóes; barras representam o desvio padrão da média;.médias entre os tratamentos -Si e +Si seguidas de asterisco $(*)$ são significativamente diferentes pelo teste- $t$ a $5 \%$ de significância.

de E. globulus infectadas por Mycosphaerella sp., onde as reduçóes de $A$ não estavam relacionadas ao aumento da resistência estomática mas sim à reduçáo da atividade da ribulose-bisfosfato (RuBP) carboxilase/oxigenase (Rubisco) e alteraçôes na capacidade de regeneração da RuBP (Pinkard e Mohammed, 2006). Pode-se inferir que as reduçôes em $A$ provocadas pela infecçáo por C. gossypii var. cephalosporioides em algodoeiro estáo relacionadas a limitaçóes no influxo de $\mathrm{CO}_{2}$ nas folhas, mas também com limitações bioquímicas para a fixaçấo de $\mathrm{CO}_{2}$ a nível de cloroplasto.
A colonização dos tecidos foliares pelo patógeno reduziu a concentração dos pigmentos nas folhas das duas cultivares de algodoeiro, principalmente as concentraçōes de $c l$, no entanto, nas plantas supridas com $\mathrm{Si}$, essa redução foi menor. No patossistema arroz-B. oryzae, a colonização dos tecidos foliares pelo patógeno em estágios mais avançados da infecção reduziu as concentrações de $c_{\mathrm{a}}$ e de $c l_{\mathrm{b}}$, porém os carotenoides foram menos prejudicados (Dallagnol et al., 2011). No patossistema milho-Exserohilum turcicum, a $c$ foi mais afetada do que a $c l_{\mathrm{b}}$ pelas toxinas secretadas pelo fungo (Chauhan et al., 1997). O fechamento estomático, devido à 

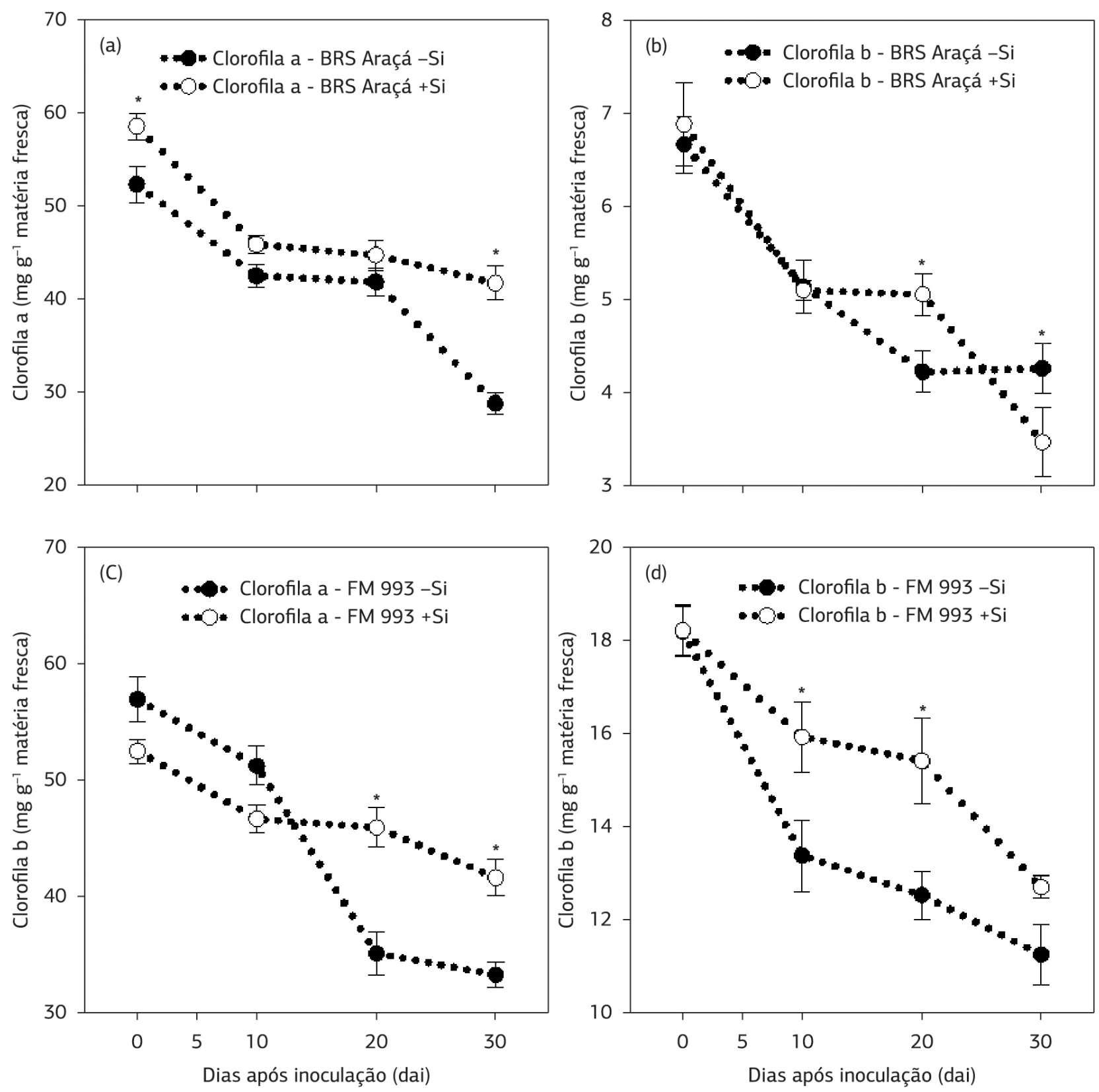

Figura 6. Concentraçấo de clorofilas a e b determinada em folhas de algodoeiro das cultivares BRS Araçá (a, b) e FM 993 (c, d) crescidas em solução nutritiva contendo $(+\mathrm{Si})$ ou não $(-\mathrm{Si})$ silício $(\mathrm{Si})$ e inoculadas com Colletotrichum gossypii var. cephalosporioides; cada ponto representa a média de quatro repetiçóes; barras representam o desvio padrão da média; médias entre os tratamentos $-\mathrm{Si}$ e $+\mathrm{Si}$ seguidas de asterisco $\left({ }^{*}\right)$ sấo significativamente diferentes pelo teste- $t$ a $5 \%$ de significância.

redução na $g_{s}$, interfere na cadeia de transferência de elétrons e reduz a entrada de $\mathrm{CO}_{2}$ nos cloroplastos durante o ciclo de Calvin, com isso há excesso de NADPH e os elétrons originários da quebra da molécula de água na fotossistema II não têm $\mathrm{NADP}^{+}$disponível para reduzi-los, levando a um forte aumento na quantidade de elétons, que, por sua vez, provocam foto-oxidação da clorofila nas antenas do fotossistema.

A infecção por C. gossypii var. cephalosporioides nas plantas das duas cultivares levou a reduçóes na quantidade de MST devido a reduçóes nas demais fraçóes, diminuindo
RMF, RMC, RMR, AFE e RAF. A infecçáo causada pelo patógeno C. gossypii var. cephalosporioides causou reduçóes nas taxas fotossintéticas e, consequentemente, menor acúmulo de matéria seca devido à redução na área foliar fotossinteticamente ativa. Além disso, é muito provável que as reduçóes em RMF, RMR, AFE e RAF sofridas pela cultivar FM 993 ocorreram em virtude da maior intensidade da ramulose, afetando mais o crescimento das plantas.

Os maiores valores de $A$ nas plantas não inoculadas e inoculadas supridas com $\mathrm{Si}$ estâo relacionados à maior condutância estomática, permitindo maior influxo de 

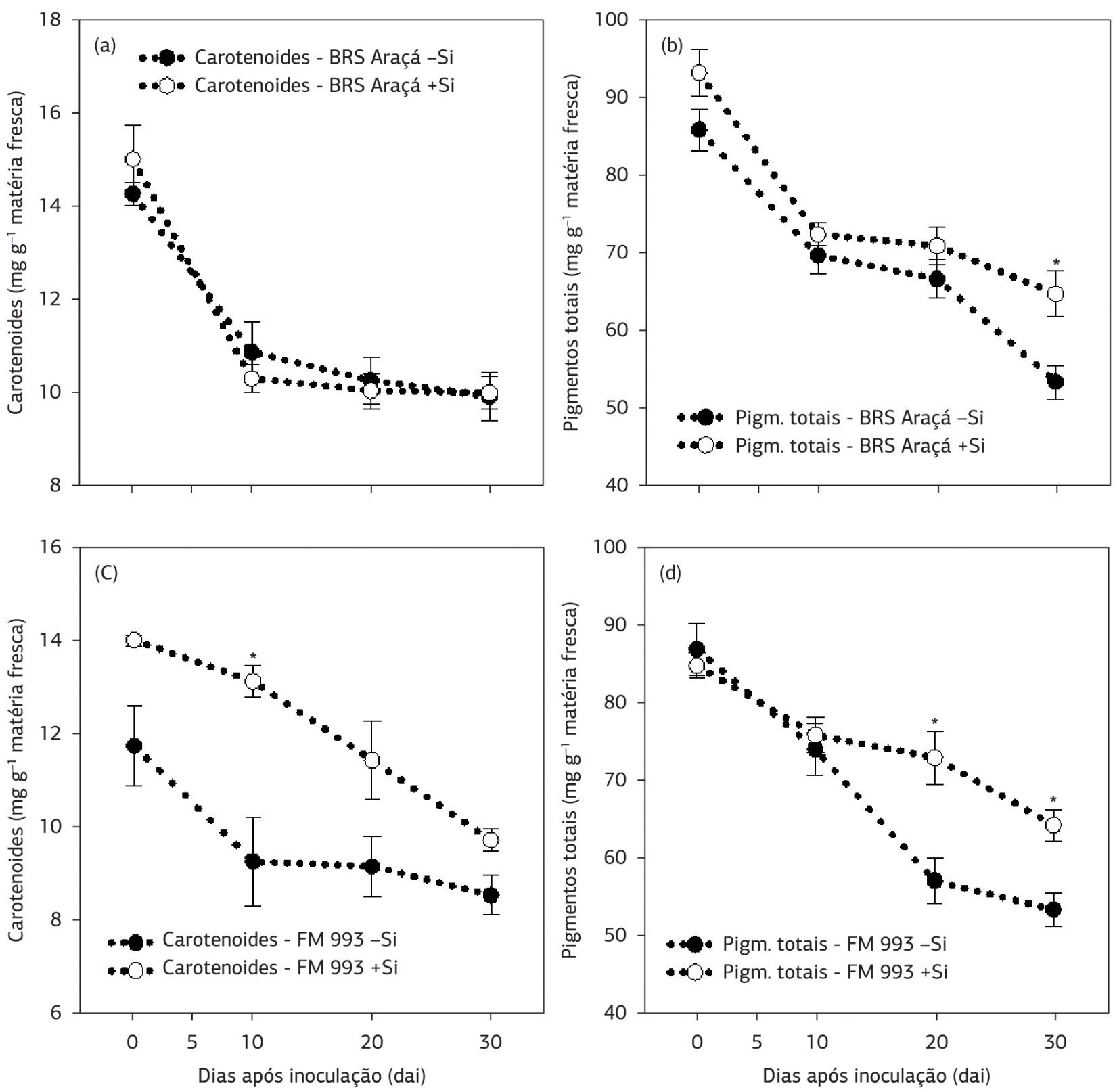

Figura 7. Concentração de carotenoides e pigmentos totais determinada em folhas de algodoeiro das cultivares BRS Araçá (a, b) e FM 993 (c, d) crescidas em solução nutritiva contendo $(+\mathrm{Si})$ ou não $(-\mathrm{Si})$ silício $(\mathrm{Si})$ e inoculadas com Colletotrichum gossypii var. cephalosporioides; cada ponto representa a média de quatro repetiçóes; barras representam o desvio padrão da média; médias entre os tratamentos - $\mathrm{Si}$ e $+\mathrm{Si}$ seguidas de asterisco $\left({ }^{*}\right)$ são significativamente diferentes pelo teste-t a $5 \%$ de significância.

$\mathrm{CO}_{2}$. Oliveira e Castro (2002) mostraram que a deposição de Si nos tricomas e estômatos de Curatella amaricana proporcionou maior abertura estomática. $\mathrm{O}$ acúmulo de $\mathrm{Si}$ nessa região permitiu a manutenção da abertura estomática e maior influxo de $\mathrm{CO}_{2}$ mesmo após a infecção. Os danos no aparato fotossintético devido à infecção por $C$. gossypii var. cephalosporioides são inevitáveis e são responsáveis pelos baixos valores de $A$.

As plantas que receberam $\mathrm{Si}$ apresentaram menores valores de $E$, consequentemente houve uma menor perda de vapor d'água em relação às plantas não supridas com esse elemento. Além disso, as plantas que receberam o $\mathrm{Si}$, tanto as sadias quanto as doentes, passaram a usar de maneira mais eficiente a água, passando a fixar uma maior quantidade de $\mathrm{CO}_{2}$ por molécula de água transpirada. Esse fato é possível devido ao acúmulo de $\mathrm{Si}$, que proporciona uma proteçáo mecânica à epiderme e ao mesmo tempo aumenta a resistência à seca - o Si acumulado nas lâminas foliares forma uma dupla camada de sílica-celulose que confere diminuição da permeabilidade ao vapor de água, o que limita a perda de água através da cutícula, reduzindo a transpiração cuticular (Ma et al., 2001; Yoshida et al., 1962). Agarie et al. (1998) 
Tabela 5. Análise de variância para as variáveis matéria seca total [MST (g)], razão de massa foliar (RMF), razão de massa caulinar (RMC), razão de massa do pecíolo (RMP), razão de massa radicular (RMR), área foliar específica [AFE $\left(\mathrm{m}^{2} \mathrm{~kg}^{-1}\right)$ ] e razão de área foliar [RAF ( $\mathrm{m}^{2}$ $\left.\mathrm{kg}^{-1}\right)$ ] obtidas de plantas de algodoeiro das cultivares BRS Araçá e FM 993 crescidas em solução nutritiva contendo (+Si) ou não (-Si) silício (Si) e avaliadas aos 30 dias após inoculação com Colletotrichum gossypii var. cephalosporioides

\begin{tabular}{|c|c|c|c|c|c|c|c|c|}
\hline \multicolumn{2}{|c|}{ Fontes de variação } & MST & RMF & RMC & RMP & RMR & AFE & RAF \\
\hline \multirow{3}{*}{ Cultivares } & BRS Araçá & 7,31 & 0,39 & 0,42 & 0,08 & 0,09 & 45,40 & 17,92 \\
\hline & FM 993 & 7,96 & 0,32 & 0,46 & 0,08 & 0,07 & 35,32 & 13,38 \\
\hline & DMS & $1,21^{\mathrm{ns}}$ & $0,03^{*}$ & $0,02^{*}$ & $0,01^{\text {ns }}$ & $0,01^{*}$ & $8,26^{*}$ & $3,67^{*}$ \\
\hline \multirow{3}{*}{ Inoculação } & $\begin{array}{l}\text { Plantas não } \\
\text { inoculadas }\end{array}$ & 10,52 & 0,37 & 0,47 & 0,09 & 0,09 & 43,24 & 17,48 \\
\hline & Plantas inoculadas & 4,75 & 0,32 & 0,43 & 0,09 & 0,07 & 39,48 & 13,83 \\
\hline & DMS & $1,21^{*}$ & $0,03^{*}$ & $0,02^{*}$ & $0,01^{\mathrm{ns}}$ & $0,01^{*}$ & $8,26^{\mathrm{ns}}$ & $3,67^{*}$ \\
\hline \multirow{3}{*}{ Silício } & $-S i$ & 6,95 & 0,32 & 0,44 & 0,09 & 0,08 & 38,66 & 12,24 \\
\hline & $+\mathrm{Si}$ & 8,32 & 0,39 & 0,45 & 0,07 & 0,08 & 48,06 & 18,07 \\
\hline & DMS & $1,21^{*}$ & $0,03^{*}$ & $0,02^{\text {ns }}$ & $0,01^{*}$ & $0,01^{\mathrm{ns}}$ & $8,26^{*}$ & $3,67^{*}$ \\
\hline \multicolumn{9}{|c|}{ Valores de F } \\
\hline & Blocos & $0,14^{\text {ns }}$ & $0,23^{\text {ns }}$ & $0,84^{\text {ns }}$ & $2,77^{\mathrm{ns}}$ & $1,07^{\text {ns }}$ & $1,00^{\text {ns }}$ & $1,05^{\text {ns }}$ \\
\hline \multicolumn{2}{|c|}{ Cultivares (C) } & $1,12^{\text {ns }}$ & $15,89^{*}$ & $6,94^{*}$ & $2,07^{\text {ns }}$ & $8,89^{*}$ & $3,74^{*}$ & $5,95^{*}$ \\
\hline \multicolumn{2}{|c|}{ Inoculação (I) } & $88,35^{*}$ & $0,99^{*}$ & $0,39^{*}$ & $2,12^{\text {ns }}$ & $21,41^{*}$ & $0,8^{\text {ns }}$ & $0,78^{*}$ \\
\hline \multicolumn{2}{|c|}{ Doses de silício (Si) } & $4,94^{*}$ & $18,80^{*}$ & $7,11^{\mathrm{ns}}$ & $10,46^{*}$ & $0,33^{\text {ns }}$ & $0,66^{*}$ & $2,31^{*}$ \\
\hline \multicolumn{2}{|r|}{$C \times 1$} & $5,39^{*}$ & $7,02^{\text {ns }}$ & $1,35^{\text {ns }}$ & $5,30^{\text {ns }}$ & $10,60^{*}$ & $7,31^{\mathrm{ns}}$ & $4,73^{\text {ns }}$ \\
\hline \multicolumn{2}{|r|}{$\mathrm{C} \times \mathrm{Si}$} & $0,10^{\text {ns }}$ & $7,64^{\mathrm{ns}}$ & $3,41^{\text {ns }}$ & $5,21^{\mathrm{ns}}$ & $0,01^{\mathrm{ns}}$ & $4,86^{\text {ns }}$ & $2,36^{\text {ns }}$ \\
\hline \multicolumn{2}{|r|}{$\mathrm{I} \times \mathrm{Si}$} & $0,13^{\text {ns }}$ & $10,33^{\text {ns }}$ & $0,01^{\text {ns }}$ & $0,78^{\text {ns }}$ & $4,18^{\text {ns }}$ & $3,61^{\mathrm{ns}}$ & $1,73^{\text {ns }}$ \\
\hline \multicolumn{2}{|r|}{$\mathrm{C} \times \mathrm{I} \times \mathrm{Si}$} & $2,88^{\text {ns }}$ & $1,93^{\text {ns }}$ & $1,50^{\text {ns }}$ & $0,66^{\text {ns }}$ & $0,13^{\text {ns }}$ & $4,01^{\mathrm{ns}}$ & $3,37^{\text {ns }}$ \\
\hline \multicolumn{2}{|r|}{ CV (\%) } & 35,54 & 29,04 & 19,28 & 30,56 & 28,59 & 43,89 & 35,15 \\
\hline
\end{tabular}

${ }^{*} \mathrm{p} \leq 0,05$ : significativo a $5 \%$ de significância pelo teste- $F$; ${ }^{*} \mathrm{p} \leq 0,05$ : significativo a $5 \%$ de significância pelo teste- $t$; ${ }^{\text {ns: }}$ năo significativo; CV: coeficiente de variação

Tabela 6. Matéria seca total (MST) (g) e razão da massa radicular (RMR) das plantas de algodoeiro das cultivares BRS Araçá e FM 993 crescidas em solução nutritiva e inoculadas com Colletotrichum gossypii var. cephalosporioides ou não

\begin{tabular}{cccccc}
\multicolumn{2}{c}{} & \multicolumn{2}{c}{ MST } & \multicolumn{2}{c}{ RMR } \\
Inoculação & Plantas não inoculadas & Plantas inoculadas & Plantas não inoculadas & Plantas inoculadas \\
\multirow{2}{*}{ Cultivares } & BRS Araçá & $9,48 \mathrm{Ab}$ & $5,13 \mathrm{Ba}$ & $0,10 \mathrm{Aa}$ & $0,07 \mathrm{Ba}$ \\
\cline { 2 - 3 } & FM 993 & $11,56 \mathrm{Aa}$ & $4,36 \mathrm{Ba}$ & $0,08 \mathrm{Ab}$ & $0,07 \mathrm{Ba}$ \\
\hline
\end{tabular}

Médias na mesma linha seguidas de letras maiúsculas diferentes ou médias na mesma coluna seguidas de letras minúsculas distintas são estatisticamente diferentes ( $\leq 0,05$ ) de acordo com o teste de Tukey

Tabela 7. Valores de correlaçáo de Pearson (acima da diagonal) e seus respectivos valores de probabilidades (abaixo da diagonal) entre as variáveis taxa de assimilação líquida de carbono $(A)$, condutância estomática $(g)$, transpiração $(E)$, razão entre concentração interna e ambiente de $\mathrm{CO}_{2}\left(C_{i} / C_{2}\right)$, eficiência instantânea no uso da água $(A / E)$, matéria seca total (MST) e índice da ramulose (IR) avaliadas em plantas de algodão supridas com silício após inoculação com Colletotrichum gossypii var. cephalosporioides

\begin{tabular}{|c|c|c|c|c|c|c|c|}
\hline Variáveis & A & $g_{\mathrm{s}}$ & $E$ & $C_{i} / C_{a}$ & $A / E_{i}$ & MST & IR \\
\hline$A$ & - & 0,6588 & 0,4211 & $-0,1816$ & 0,6980 & 0,5460 & $-0,8268$ \\
\hline$g_{\mathrm{s}}$ & $0,0001^{*}$ & - & 0,3140 & $-0,2616$ & 0,5433 & 0,5408 & $-0,7044$ \\
\hline$E$ & $0,0001^{*}$ & $0,0005^{*}$ & - & 0,9812 & 0,2856 & 0,4329 & $-0,4622$ \\
\hline$C_{\mathrm{i}} / C_{\mathrm{a}}$ & $0,040^{*}$ & $0,003^{*}$ & $0,002^{*}$ & - & $-0,6779$ & $-0,6837$ & 0,2208 \\
\hline$A / E$ & $0,0001^{*}$ & $0,0001^{*}$ & $0,0016^{*}$ & $0,0001^{*}$ & - & $-0,4400$ & $-0,6495$ \\
\hline MST & $0,0001^{*}$ & $0,0001^{*}$ & $0,0001^{*}$ & $0,040^{*}$ & $0,0001^{*}$ & - & $-0,5863$ \\
\hline IR & $0,0001^{*}$ & $0,0001^{*}$ & $0,0001^{*}$ & $0,0010^{*}$ & $0,0001^{*}$ & $0,0001^{*}$ & - \\
\hline
\end{tabular}

${ }^{*} \mathrm{p} \leq 0,05$ : significativo a $5 \%$ de significância pelo teste- $F$

encontraram menor taxa de transpiração em plantas de arroz que cresceram em meio que havia Si. Hattori et al. (2005) observaram maior taxa de transpiração, condutância estomática e acúmulo de matéria seca em plantas de sorgo submetidas a déficit hídrico e supridas com $\mathrm{Si}$, em relação a plantas não supridas. Os resultados ora obtidos corroboram outros encontrados por Chen et al. (2011), que obtiveram reduçôes na $E$ e $C_{\mathrm{i}}$, aumentos em $g_{\mathrm{s}}$, $A$ e acúmulo de matéria seca em plantas de arroz supridas com $S$ i sob condições de estresse hídrico.

A infecção por C. gossypii var. cephalosporioides reduziu significativamente as concentraçóes de $c l a, c l_{\mathrm{b}}$ e carotenoides, mas nas plantas que receberam Si essas concentraçóes foram maiores. $\mathrm{O} \mathrm{Si}$ afetou as concentrações de pigmentos 
possivelmente devido ao efeito de sua atuação como barreira física, impedindo a penetração das hifas do patógeno, o que reduziu os índices de infecção, comprovados pelas menores AACIR. Chen et al. (2011) mostraram aumentos nas concentraçóes de clorofilas em plantas de arroz sob estresse hídrico, isso pode ter alguma relação com a maior eficiência fotoquímica das plantas. Adatia e Besford (1986) relatam que a aplicação de $\mathrm{Si}$ aumentou a concentração de pigmentos e a atividade da rubisco em plantas de pepino. Os resultados obtidos neste estudo permitem inferir que o Si pode exercer influência positiva sobre a capacidade fotossintética das plantas de algodoeiro.

\section{CONCLUSÃO}

A infecção por C. gossypii var. cephalosporioides afetou a fisiologia das plantas de algodoeiro, alterando a sua capacidade fotossintética. $\mathrm{O}$ fornecimento de $\mathrm{Si}$ às plantas de algodoeiro potencializou a $A$ devido ao aumento na $g_{\mathrm{s}} \mathrm{e}$ na fixação de $\mathrm{CO}_{2}$, além de redução na $E$. A manutenção da taxa fotossintética das plantas de algodoeiro durante o processo infeccioso contribui para maior resistência à ramulose.

\section{AGRADECIMENTOS}

À Fundaçáo de Amparo à Pesquisa do Estado de Minas Gerais (Fapemig), pelo recurso financeiro (Processo APQ01072-10). Ao Conselho Nacional de Desenvolvimento Científico e Tecnológico (CNPq), pelas bolsas de doutorado e iniciação científica concedidas a A. M. N. M. Guerra e A. F. Barros, respectivamente, e pelas bolsas de produtividade em pesquisa dos professores F. A. Rodrigues e P. G. Berger.

\section{REFERÊNCIAS}

ADATIA, M.H.; BESFORD, R.T. The effects of silicon on cucumber plants grown in recirculating nutrient solution. Annals of Botany, v. 58, p.343-351, 1986.

AGARIE, S.; UCHIDA, H.; AGATA, W.; KUBOTA, F.; KAUFMAN, P.B. Effects of silicon on transpiration and leaf conductance in rice plants (Oryza sativa L.). Plant Production Science, v.1, p.89-95, 1998. http://dx.doi.org/10.1626/pps.1.89

ALVES, A.A.; GUIMARÃES, L.M.S.; CHAVES, A.R.M.; DAMATTA, F.M.; ALFENAS, A.C. Leaf gas Exchange and chlorophyll a fluorescence os Eucalyptus urophylla in response to Puccinia psidii infection. Acta Physiology Plant, v.33, p.1831-1839, 2011. http://dx.doi.org/10.1007/ s11738-011-0722-z
BASTIAANS, L. Effects of leaf blast on photosynthesis of rice. Leaf photosynthesis. Neth Journal Plant Pathology, v.99, p.197-203, 1993. http://dx.doi.org/10.1007/BF01974664

BERGER, S.; SINHA, A.K.; ROITSCH, T. Plant physiology meets phytopathology: plant primary metabolism and plant-pathogen interactions. Journal of Experimental Botany, v.58, p.4019-4026, 2007. PMid:18182420. http://dx.doi.org/10.1093/jxb/erm298

CHEN, W.; YAO, X.; CAI, K.; CHEN, J. Silicon alleviates drought stress of rice plants by improving plant water status, photosynthesis and mineral nutrient absorption. Biological Trace Elements Residuos, v.142, p.67-76, 2011. PMid:20532668. http://dx.doi.org/10.1007/ s12011-010-8742-x

CHAUHAN, R.S.; SINGH, B.M.; DEVELASH, R.K. Effect of toxic compounds of Exserohilum turcicum on chlorophyll content, callus growth and cell viability of susceptible and resistant inbred lines of maize. Journal of Phytopatholology, v.145, p.435-440, 1997. http:// dx.doi.org/10.1111/j.1439-0434.1997.tb00346.x

COSTA, A.S.; FRAGA JÚNIOR, C.G. Superbrotamento ou ramulose do algodoeiro. Campinas: Instituto Agronômico, 1937. 23p. (Boletim Técnico, 19)

DALLAGNOL, L.J.; RODRIGUES, F.A.; MARTINS, S.C.V.; CAVATTE, P.C.; DAMATTA, F.M. Alterations on Rice leaf physiology during infection by Bipolaris oryzae. Australian Plant Pathology, v.40, p.360-365, 2011. http://dx.doi.org/10.1007/s13313-011-0048-8

FENG, J.; SHI, Q.; WANG, X. Effects of exogenous silicon on photosynthetic capacity and antioxidant enzyme activities in chloroplast of cucumber seedlings under excess manganeses. Agricultural Sciences in China, v.8, p.40-50, 2009. http://dx.doi.org/10.1016/S16712927(09)60007-9

GONG, H.; CHEN, K.; CHEN, G.; WANG, S.; ZHANG, C. Effects of silicon on the growth of wheat and its antioxidative enzymatic system. Chinese Journal of Soil Science, v.34, p.55-57, 2003.

GUNES, A., INAL, A.; BAGCI, E.G.; PILBEAM, D.J. Siliconmediated changes of some physiological and enzymatic parameters symptomatic for oxidative stress in spinach and tomato grown in sodic-B toxic soil. Plant and Soil, v.290, p.103-114, 2007. http:// dx.doi.org/10.1007/s11104-006-9137-9

HATTORI, T.; INANAGA, S.; ARAKI, H.; AN, P.; MORITA, S.; LUXOVA, M.; LUX, A. Application of silicon enhanced drought tolerace in Sorghum bicolor. Physiologia Plantarum, v.123, p.459466, 2005. http://dx.doi.org/10.1111/j.1399-3054.2005.00481.x

HOAGLAND, D.R.; ARNON, D.I. The water culture method for growing plants without soil. California Agricultural Experiment Station, v.347, p.32, 1950.

HODGES, C.F.; CAMPBELL, D.A. Endogenous ethane and ethylene of Poa pratensis leaf blades and leaf chlorosis in response to biologically active products of Bipolaris sorokiniana. European Journal Plant Pathology, v.105, p.825-829, 1999. http://dx.doi. org/10.1023/A:1008750902655

HODSON, M.J.; SANGSTER, A.G. Silicon and abiotic stress. In: MATOH, T. (Ed.). Second Silicon in Agriculture Conference. Tokyo: Press-Net, 2002. p.99-104. 
HUNT, R. (1990). Basic growth analysis. London: Unuin Hyman, Academic Division of Unwin Hyman Ltd, 1990. 112p. http://dx.doi. org/10.1007/978-94-010-9117-6

KORNDÖRFER, G.H.; PEREIRA, H.S.; NOLLA, O.A. Análise de silício: solo, planta e fertilizante. Uberlândia: Grupo de Pesquisa em Silício, ICIAG, Universidade Federal de Uberlândia, 2004. 34p.

LIANG, Y.C.; ZHANG, W.H.; CHEN, Q.; LIU, Y.L.; DING, R.X. Effect of exogenous silicon ( $\mathrm{Si}$ ) on $\mathrm{H}+$-ATPase activity, phospholipids and fluidity of plasma membrane in leaves of salt-stressed barley (Hordeum vulgare L.). Environmental and Experimental Botany, v.57, p.212-219, 2006. http://dx.doi.org/10.1016/j.envexpbot.2005.05.012

LICHTENTHALER, H.K.; MIEHÉ, J.A. Fluorescence imaging as a diagnostic tool for plant stress. Trends Plant Science, v.2, p.316-320, 1997. http://dx.doi.org/10.1016/S1360-1385(97)89954-2

LICHTENTHALER, H.K. Chlorophylls and carotenoids, the pigments of photosynthetic biomembranes. In: DOUCE, R., PACKER, L. (Ed.). Methods in enzymology. New York: Academic, 1987. p.350-382.

MA, J.F.; MIYAKE, Y.; TAKAHASHI, E. Silicon as a beneficial element for crop plants. In: DATNOFF, L. E., SNEDER, G. H., KORNDÖRFER, G. H. (Ed.). Silicon in Agriculture. Amsterdam: Elsevier Science, 2001. p.17-39. http://dx.doi.org/10.1016/S09283420(01)80006-9

MA, J.F.; TAKAHASHI, E. Soil, fertilizer and plant silicon research in Japan. Tokio: Elsevier Science, 2002. 281p.

MARUR, C.J.; RUANO, O. A reference system of determination of cotton plant development. Revista de Oleaginosas e Fibrosas, v.5, p.313-317, 2001.

MATEO, A.; MUHLENBOCK, P.; RUSTERUCCI, C.; CHANG, C.C., MISZALSKI, Z.; KARPINSKA, B.; PARKER, J.E.; MULLINEAUX, P.M.; KARPINSKI, S. Lesion simulating disease is required for acclimation to conditions that promote excess excitation energy. Plant Physiology, v.136, p.2818-2830, 2004. PMid:15347794 PMCid:PMC523344. http://dx.doi.org/10.1104/pp.104.043646

MATSUDA, R.; OHASHI-KANEKO, K.; FUJIWARA, K.; GOTO, E.; KURATA, K. Photosynthetic characteristics of rice leaves grown under red light with or without supplemental blue light. Plant Cell Physiology, v.45, p.1870-1874, 2004. PMid:15653806. http://dx.doi. org/10.1093/pcp/pch203

McKINNEY, H.H. Influence of soil temperature and moisture on infection of wheat seedlings by Helminthosporium sativum. Journal of Agricultural Research, v.26, p.195-218, 1923.
MEHTA, Y.R.; ZANDONÁ, C.; BIBANCO, K.; ALMEIDA, W.P.; TEIXEIRA, E. A.; CUNHA, H.C.; ERIVALDO, J. Resposta diferencial de cultivares comerciais do algodoeiro a Colletotrichum gossypii var. cephalosporioides. Summa Phytopathologica, v.60, p.142-145, 2005.

OLIVEIRA, L.A.; CASTRO, N.M. Ocorrência de sílica nas folhas de Curatella americana L. e de Davilla elliptica St. Hil. Revista Horizonte Científico, v.4, p.1-16, 2002.

PINKARD, E.A.; MOHAMMED, C.L. Photosynthesis of Eucalyptus globulus with Mycosphaerella leaf disease. New Phytologist, v.170, p.119-127, 2006. PMid:16539609. http://dx.doi.org/10.1111/j.14698137.2006.01645.x

RANGANATHAN, S.; CHANDRASEKHARA RAO, C.; SUVARCHALA, V.; RAJESH, Y.B.R.D.; JAGDESH, B. Solubilization of silica: synthesis, charactarization and study of penta-coordinated pyridine N-oxide silicon complexes. Journal Chemistry Science, v.116, p.169-174, 2006. http://dx.doi.org/10.1007/BF02708221

RIBEIRO, R.V.; MACHADO, E.C.; OLIVEIRA, R.F. Early photosynthetic responses of sweet orange plants infected with Xylella fastidiosa. Physiology and Molecular Plant Pathology, v.62, p.167-173, 2003. http://dx.doi.org/10.1016/S0885-5765(03)00038-9

RODRIGUES, F.A.; BENHAMOU, N.; DATNOFF, L.E.; JONES, J.B.; BÉLANGER, R. R. Ultrastructural and cytochemical aspects of silicon-mediated rice blast resistance. Phytopathology, v.93, p.535-546, 2003. PMid:18942975. http://dx.doi.org/10.1094/ PHYTO.2003.93.5.535

SUASSUNA, N.D.; COUTINHO, W.M. Manejo das principais doenças do algodoeiro no cerrado brasileiro. In: FREIRE, E.C. (Ed.). Algodão no Cerrado do Brasil. 2.ed. Brasília: Abrapa, 2011. p.567-612.

SCHOLES, J.; ROLFE, S.A. Photosynthesis in localized regions of oat leaves infected with crown rust (Puccinia coronata): quantitative imaging of chlorophyll fluorescence. Planta, v.199, p.573-582, 1996. http://dx.doi.org/10.1007/BF00195189

SHANER, G.; FINNEY, R.E. The effect of nitrogen fertilization on the expression of slow-mildewing resistance in Knox wheat. Phytopathology, v.67, p.1051-1056, 1977. http://dx.doi.org/10.1094/Phyto-67-1051

YOSHIDA, S.; OHNISHI, Y.; KITAGISHI, K. Chemical forms, mobility and deposition of silicon in rice plants. Soil Science Plant Nutrition, v.8, p.15-21, 1962. http://dx.doi.org/10.1080/0038076 8.1962.10430992 